\title{
TRATAMENTO DE RESÍDUOS E EFLUENTES ATRAVÉS DE SISTEMAS BIOELETROQUÍMICOS: UMA REVISÃO DA LITERATURA
}

\author{
Maick Meneguzzo Prado' \\ Elisângela Edila Schneider ${ }^{2}$ \\ Hugo Moreira Soares ${ }^{3}$
}

\begin{abstract}
RESUMO
Os sistemas bioeletroquímicos são uma tecnologia emergente, a qual utiliza microrganismos para converter a energia química armazenada em materiais biodegradáveis para produzir energia elétrica e produtos químicos de forma mais sustentável do que nos processos convencionais. Dentre os materiais biodegradáveis, muitos resíduos sólidos e efluentes líquidos podem ser utilizados, oferecendo flexibilidade para reações anódicas e catódicas. Em sua estrutura, esses sistemas possuem basicamente uma câmara do ânodo, onde os materiais biodegradáveis são oxidados e geram elétrons livres. Em alguns sistemas com a câmara do cátodo, os elétrons livres passam a gerar corrente na própria célula. Essa tecnologia possui diferentes aplicações como geração de energia elétrica, produção de compostos químicos específicos, dessalinização da água do mar e remediação de solos contaminados. Este trabalho traz uma revisão da literatura sobre todos os sistemas mencionados, bem como as principais reações bioquímicas envolvidas, fornecendo informações e discussões sobre o desenvolvimento atual dessa promissora tecnologia e algumas dificuldades pertinentes, como a produção de energia em larga escala.
\end{abstract}

Palavras-chave: Sistemas bioeletroquímicos; Célula de combustível microbiana; Geração de energia elétrica; Tratamento de resíduos.

\footnotetext{
1 Doutorando do Programa de Pós-Graduação em Engenharia Química, Universidade Federal de Santa Catarina (UFSC). E-mail: maickmeneguzzo@gmail.com

2 Pós-doutoranda do Programa de Pós-Graduação em Engenharia Química, Universidade Federal de Santa Catarina (UFSC). E-mail: elis_schneider@yahoo.com.br

3 Docente do Programa de Pós-Graduação em Engenharia Química, Universidade Federal de Santa Catarina (UFSC).E-mail: hugo.moreira.soares@ufsc.br
} 
WASTEWATER TREATMENT THROUGH BIOELECTROCHEMICAL SYSTEMS: A LITERATURE REVIEW

\begin{abstract}
Bioelectrochemical systems are an emerging technology that uses microorganisms to convert stored chemical energy into biodegradable materials to produce electrical energy and chemicals more sustainably than conventional processes. Among the biodegradable materials, many solid residues and liquid effluents can be used, offering flexibility for anodic and cathodic reactions. In their structure, these systems basically have an anode chamber, where biodegradable materials are oxidized and generate free electrons. In some systems with the cathode chamber, free electrons start to generate current in the cell itself. This technology has different applications such as electricity generation, production of specific chemical compounds, seawater desalination and contaminated soil remediation. This work brings a literature review on all the systems mentioned, as well as the main biochemical reactions involved, providing information and discussions on the current development of this promising technology and some pertinent difficulties, such as large-scale energy production.
\end{abstract}

Keywords: Microbial electrochemical systems. Microbial Fuel Cell. Electricity generation. Wastewater treatment.

\title{
1 INTRODUÇÃO
}

O Dr. Richard Smalley, um dos laureados do Prêmio Nobel de 1996 na área de Química, afirmou em 2003 que: "a energia é o desafio mais crítico que a humanidade enfrenta" (RITTER, 2003). Isso vai ao encontro com as estimativas atuais de que mais de $85 \%$ da energia utilizada mundialmente é derivada de combustíveis fósseis (petróleo, carvão e gás natural) (U.S. ENERGY INFORMATION ADMINISTRATION, 2019). Outras projeções indicam que no ano de 2250 as fontes energéticas derivadas de combustíveis, que não são sustentáveis, estarão esgotadas (MAGGIO; CACCIOLA, 2012). Desta forma, para lidar com esse problema, a produção de energia através de recursos renováveis vem se intensificando nos últimos anos e sua projeção para 2050 é que atinja um patamar de $30 \%$ do total da energia produzida. (U.S. ENERGY INFORMATION ADMINISTRATION, 2019).

A maioria dos processos industriais consome grande quantidade de energia elétrica, dentre eles os sistemas de tratamento de resíduos e efluentes com suas técnicas convencionais, principalmente devido à etapa de aeração (HE et al., 2019; AWE; LIU; ZHAO, 2016). Uma fonte alternativa de energia renovável que vem sendo 


\section{¿UISUl 3nims}

investigada de forma mais intensa nos últimos 20 anos são os sistemas bioeletroquímicos. Esta tecnologia apresenta algumas vantagens frente aos sistemas convencionais de tratamento biológico de resíduos, como a eficiência de remoção de contaminantes e concomitante geração de bioeletricidade, com redução no consumo energético e na produção de lodo (SUN et al., 2016).

Esses sistemas bioeletroquímicos recebem avanços tecnológicos constantes, avaliando-se reações eletroquímicas abióticas clássicas e físicas. Cerca de $75 \%$ dos estudos nesta grande área estão voltados para as biocélulas combustíveis (MFC) (do termo em inglês microbial fuel cell), que possuem vantagens em relação às células combustíveis convencionais, como a possibilidade de uso em baixas temperaturas, com valores de $\mathrm{pH}$ próximos da neutralidade, utilização de biomassa e impacto ambiental moderado (SANTORO et al., 2017). Geralmente esses sistemas utilizam microrganismos de baixo custo que oxidam compostos orgânicos, transferindo elétrons para o ânodo e gerando excedentes de energia elétrica de 10 a 20\% além do consumo do próprio sistema e uma produção de lodo que pode ser até $70 \%$ menor do que a observada em tratamentos convencionais de resíduos (WANG; REN, 2013).

A sigla BES (Bioelectrochemical Systems) é amplamente adotada pela comunidade científica, todavia pode-se utilizar também 0 termo Microbial Electrochemical Systems (HARNISCH; SCHRÖDER, 2010; LOGAN; RABAEY, 2012). Neste trabalho iremos adotar a terminologia BES.

Outros sistemas bioeletroquímicos geralmente podem ser resumidos pela sigla MXC, onde o "X" é referente a cada aplicação específica, e o "MC" à célula microbiana. Assim, tem-se as células microbianas de: dessalinização (MDC), eletrólise com produção de hidrogênio (MEC), eletrossíntese para síntese de contaminantes orgânicos (MES), remediação de contaminantes subterrâneos (MRC), solares para produção de energia e produtos agregados (MSC), entre outras (HARNISCH; SCHRÖDER, 2010; WANG; REN, 2013).

Quase todos os BES possuem um princípio de funcionamento comum: um ânodo em que substratos biodegradáveis, como resíduos e compostos orgânicos, são oxidados por microrganismos e acabam gerando elétrons que podem ser utilizados de diversas formas no cátodo. Esses sistemas vêm sendo estudados intensivamente nas últimas duas décadas, proporcionando desenvolvimento interdisciplinar e 


\section{GESTÃO \& SUSTENTABILIDADE} AMBIENTAL

\section{¿UISUl}

integração para pesquisadores de bioquímica, microbiologia, eletroquímica, ciência de materiais, engenharias e áreas conjuntas para aplicações e viabilidade dos sistemas em escala industrial (FORNERO; ROSENBAUM; ANGENENT, 2010; SARATALE et al., 2017; WANG; REN, 2013). Cabe ressaltar que essa tecnologia possui eletroquímica microbiana amplamente inexplorada e oferece, em especial para a engenharia diversas funções flexíveis, desde análise de reações bioquímicas até configuração desses sistemas (SANTORO et al., 2017; WINFIELD et al., 2016).

Os BES podem fornecer a possibilidade de redução de custos operacionais dos sistemas de tratamento de resíduos e efluentes com a geração de energia elétrica proveniente de seus mecanismos, o que não ocorre atualmente nos processos convencionais. Atualmente a única tecnologia existente em escala comercial capaz de gerar energia elétrica a partir de efluentes e resíduos é a digestão anaeróbia, porém, esta geração depende da conversão do biometano, etapa que ainda hoje exibe baixo rendimento, entre 20 e 35\% (LIMA; PASSAMANI, 2012).

Neste contexto, o objetivo deste estudo foi verificar o estado da arte a respeito dos sistemas bioeletroquímicos e suas aplicações, além da sua relação com a potencial geração de energia elétrica e tratamento de resíduos e efluentes. É realizada uma análise crítica das metodologias de elaboração dos sistemas BES e também uma apresentação de suas variantes e configurações.

\section{METODOLOGIA}

A metodologia foi aplicada executando as etapas determinadas na Figura 1, e as ações prosseguiram conforme abordagem de Metodologia para Itens de Relatório Preferenciais para Revisão Sistemática e Metanálise (PRISMA) (MOHER et al., 2010).

Figura 1 - Etapas para desenvolvimento da pesquisa.

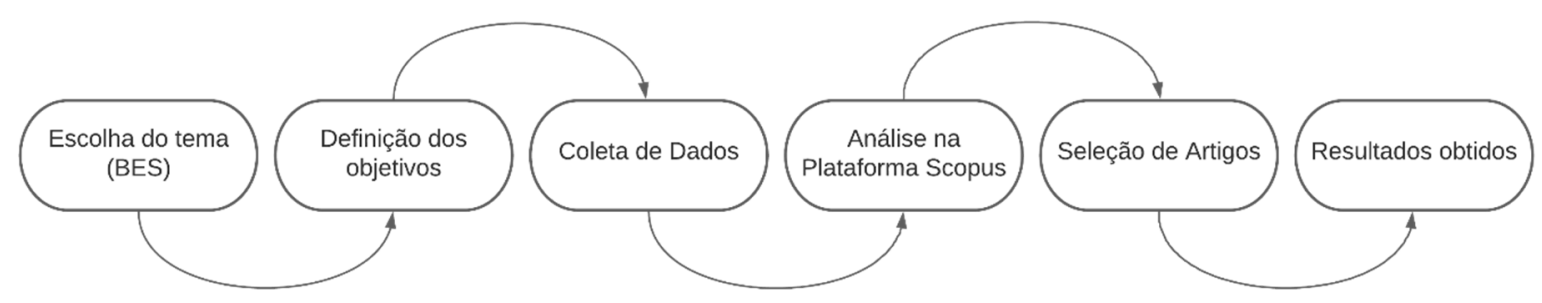

Fonte: Autores, 2020. 


\section{¿UNISUl}

\subsection{ESCOLHA DO TEMA E DEFINIÇÃO DOS OBJETIVOS}

O tema foi escolhido com base na importância dos sistemas bioeletroquímicos no tratamento de diferentes resíduos, efluentes e aplicações, além da geração energética como fonte renovável e na difusão do conhecimento na área. Fazendo, assim, parte dos objetivos analisar metodologias e variantes desses sistemas.

\subsection{COLETA DE DADOS E ANÁLISE NA PLATAFORMA SCOPUS E SELEÇÃO DE ARTIGOS}

A abordagem do PRISMA, proposta por Moher et al. (2010), foi seguida para condução da Revisão Sistemática de Literatura neste estudo. Assim, a seleção de trabalhos científicos foi a primeira etapa, direcionada para produções a partir do ano de 2000, sendo a plataforma Scopus utilizada para o banco de dados. O processo de inclusão e eliminação dos trabalhos científicos seguiu critérios específicos, que foram definidos com base nos objetivos deste trabalho, conforme apresentado no Quadro 1, seguindo a definição de critérios proposta por Liao et al. (2017).

Quadro 1 - Critérios de inclusão e exclusão dos artigos

\begin{tabular}{|l|l|l|}
\hline \multirow{4}{*}{ Inclusã } & Critério & \multicolumn{1}{c|}{ Explicação } \\
\cline { 2 - 3 } $\mathbf{0}$ & $\begin{array}{l}\text { Intimamente } \\
\text { relacionado } \\
\mathbf{( R C )}\end{array}$ & $\begin{array}{l}\text { Os esforços de pesquisa do artigo são explicitamente dedicados a } \\
\text { sistemas bioeletroquímicos. Período de tempo: Ano 2000 até } \\
\text { 30/11/2019; Assunto: Sistemas bioeletroquímicos; Tipo de } \\
\text { Documento: Artigo; Tipo de fonte: Plataforma Scopus em língua } \\
\text { inglesa. }\end{array}$ \\
\hline \multirow{5}{*}{ Exclusão } & $\begin{array}{l}\text { Motivo do } \\
\text { mecanismo de } \\
\text { pesquisa }\end{array}$ & $\begin{array}{l}\text { Um artigo possui apenas o título, o resumo e as palavras-chave em } \\
\text { inglês, mas não o texto completo. }\end{array}$ \\
\cline { 2 - 3 } & $\begin{array}{l}\text { Sem texto } \\
\text { completo } \\
\text { (STC) }\end{array}$ & Um trabalho sem o texto completo. \\
\hline
\end{tabular}




\section{GESTÃO \& SUSTENTABILIDADE AMBIENTAL}

\section{¿unisul}

\begin{tabular}{|c|c|}
\hline $\begin{array}{l}\text { Não } \\
\text { relacionado } \\
\text { (NR) }\end{array}$ & $\begin{array}{l}\text { NR1: O artigo não está alinhado com a pesquisa, apenas contém } \\
\text { palavras-chave. } \\
\text { NR2: O artigo está duplicado, nas palavras-chave pesquisadas. }\end{array}$ \\
\hline $\begin{array}{c}\text { Relacionado } \\
\text { livremente (RL) }\end{array}$ & $\begin{array}{l}\text { Um artigo não se concentra na discussão de sistemas } \\
\text { bioletroquímicos. Em que: } \\
\text { LR1: BES são usados apenas como exemplo de fato; } \\
\text { LR2: BES são usados apenas como parte de sua direção de pesquisa } \\
\text { futura; } \\
\text { LR3: BES é usado apenas em palavras-chave e/ou referências; } \\
\text { LR4: Pesquisas que não abordam o contexto dos sistemas } \\
\text { bioeletroquímicos. }\end{array}$ \\
\hline
\end{tabular}

Fonte: Adaptado de Liao et al.,2017.

Na Figura 2 é demonstrado o passo a passo seguido na metodologia PRISMA. Figura 2 - Passo a passo da metodologia PRISMA

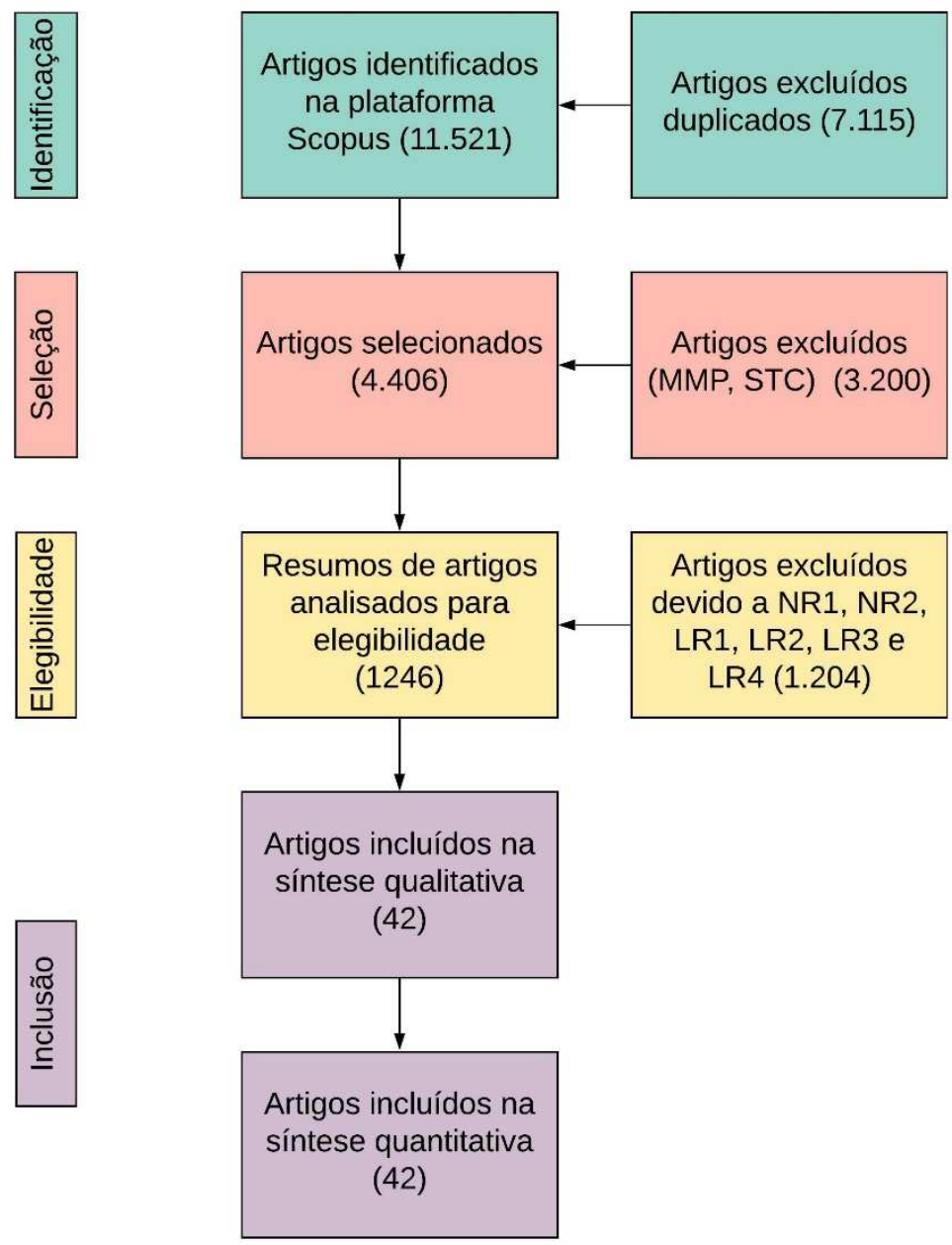

Fonte: Adaptado de Uhlmann e Frazzon, 2018.

Revista Gestão e Sustentabilidade Ambiental., v. 10, n. 3, p. 377-396, set. 2021. 


\section{GESTÃO \& SUSTENTABILIDADE} AMBIENTAL

\section{¿UISUl}

\section{RESULTADOS E DISCUSSÕES}

Os artigos utilizados para esta revisão foram na sua maioria publicados no ano de 2012. Isso pode ser explicado, pois os conhecimentos na área foram mais consolidados na primeira década deste século e, assim, suas funcionalidades e aplicações mais evidentes. Os dados apresentados a seguir constituem a revisão da literatura.

\subsection{SISTEMAS BIOELETROQUÍMICOS}

A capacidade de transferência de elétrons de microrganismos para eletrodos foi descrita pela primeira vez por Potter em 1911 (POTTER, 1911). Com essa descoberta desenvolveram-se nas últimas décadas os BES (SARATALE et al., 2017). Várias pesquisas envolvendo esses sistemas vêm ganhando atenção, conforme podese verificar no aumento de publicações em plataformas de conhecimento científico, apresentado na Figura 3 com os artigos publicados com alguns termos nessa área no período entre 1999 e 2019.

Figura 3 - Número de artigos publicados nas plataformas Scopus para sistemas bioeletroquímicos
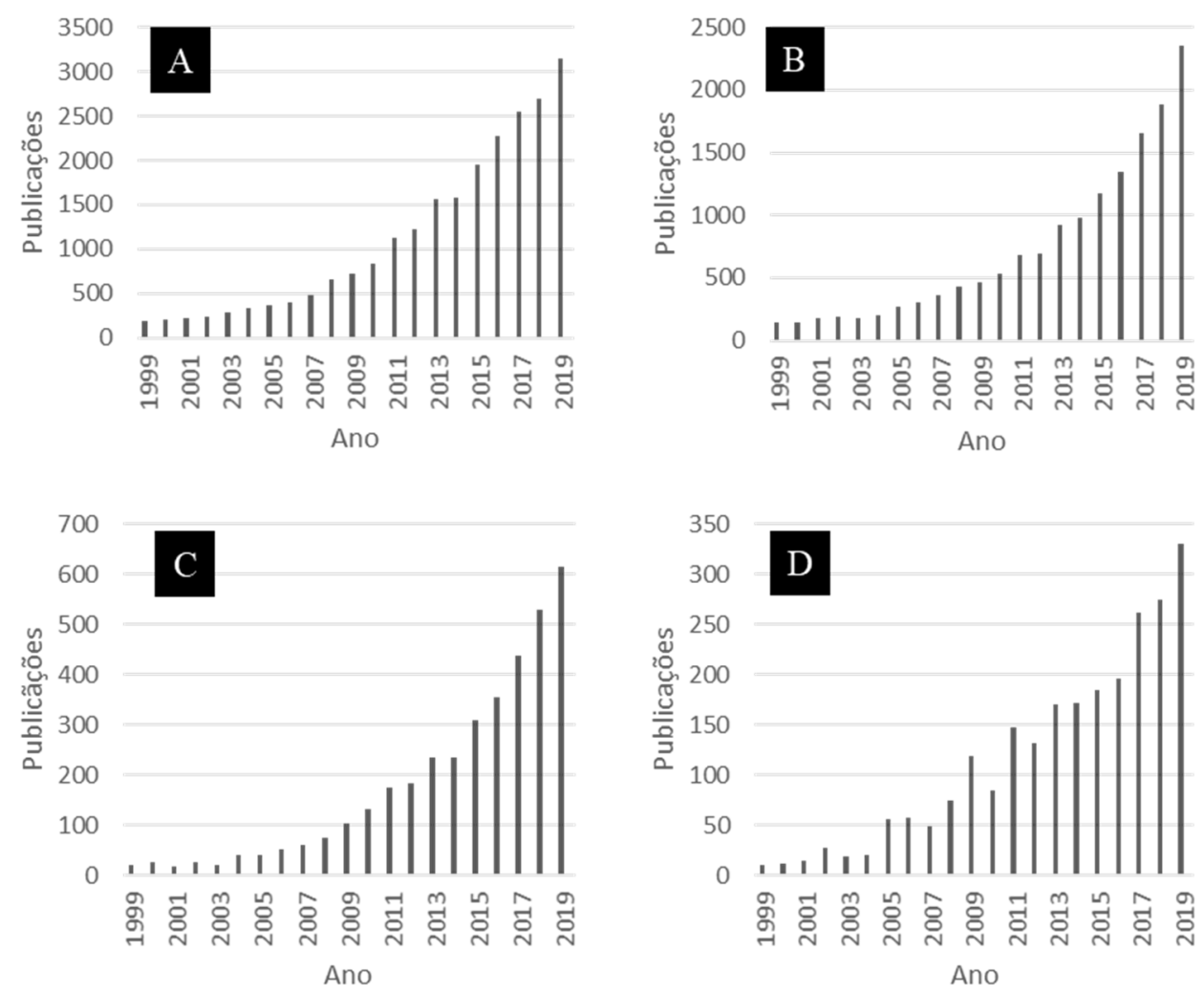

Legenda: A) MFC; B) BES; C) MEC; D) MDC.

Fonte: Scopus, 2020. 


\section{GESTÃO \& SUSTENTABILIDADE AMBIENTAL

Os BES têm capacidade de converter energia química em energia elétrica, combustíveis ou produtos bioquímicos, através do biocatalisador (microrganismos ou enzimas), sendo que a interação eletroquímica entre os microrganismos possui função crucial para funcionamento desses sistemas (WANG et al., 2015). Uma configuração básica dos BES está apresentada na Figura 4, onde o substrato é degradado através de reações bioquímicas que auxiliam na formação do biofilme. Os microrganismos ficam agregados ao eletrodo, realizando reações eletroquímicas que geram elétrons livres que são conduzidos para o cátodo através da diferença de potencial. A energia elétrica é então gerada a partir dessa diferença de potencial entre os canais anódico e catódico. Inúmeros substratos podem ser utilizados no ânodo, como, por exemplo, águas residuais, sedimentos, resíduos, dentre outros.

Figura 4 - Princípio de funcionamento de um BES

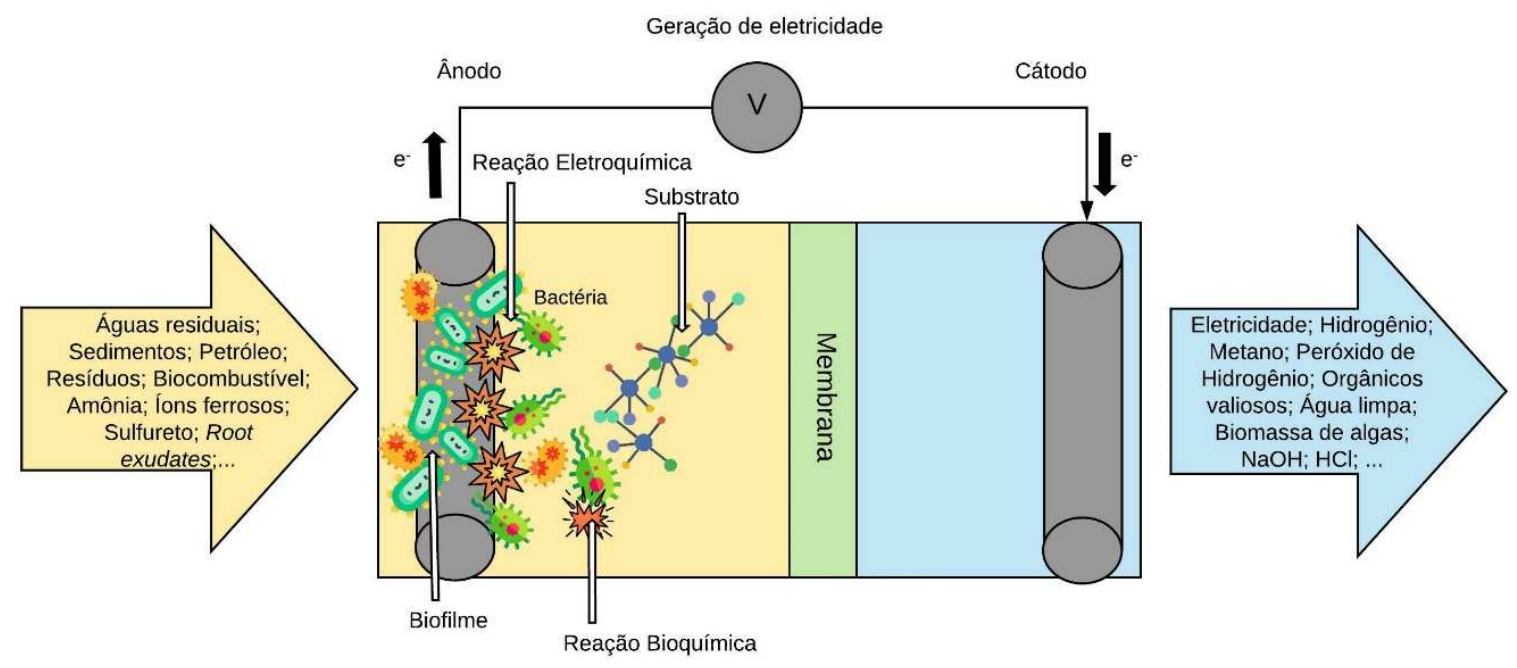

Fonte: Autores, 2020.

Muitas reações podem ocorrer nas câmaras constituintes dos BES devido à presença do biofilme aderido, e em alguns casos a microrganismos diretamente catalisados eletroquimicamente. Moléculas maiores podem ser degradadas e convertidas em moléculas mais simples no ânodo. Ocorrem também reações que geram hidrogênio, etanol e ácidos graxos que podem ser utilizados na geração energética. As reações de geração de energia elétrica ou formação de produtos químicos de interesse financeiro ocorrem no cátodo (LOGAN; RABAEY, 2012). 
As aplicações são diversas, e para cada tipo de aplicação, diferentes tipos de BES estão em processo contínuo de desenvolvimento e otimização (WANG; REN, 2013). Nos tópicos 3.1.1 a 3.1.6 estão detalhados os principais tipos de BES, conforme seu funcionamento e aplicação.

\subsubsection{CÉLULA COMBUSTÍVEL MICROBIANA}

Nos últimos 20 anos, a tecnologia das MFC vem chamando a atenção da comunidade científica, principalmente devido à capacidade de transformação de resíduos e poluentes orgânicos em eletricidade por meio de reações eletroquímicas (catódicas e anódicas), e catalíticas microbianas/enzimáticas/abióticas (SANTORO et al., 2017; WINFIELD et al., 2016).

Nas MFC, ocorre a conversão direta de energia química em energia elétrica devido a uma série de reações de oxidação-redução. Essa célula pode ser considerada como um sistema eletroquímico biocatalisador (MOHAN et al., 2014; RAHIMNEJAD; ADHAMI, 2015), que se concentra na produção de eletricidade a partir de materiais biodegradáveis (WANG; REN, 2013). As principais reações em meia célula (ânodo e cátodo) para degradação e conversão de carbono e nitrogênio que ocorrem nas MFC são apresentadas no Quadro 2. O princípio deste sistema baseiase no fato de que substratos orgânicos são oxidados por bactérias eletroativas na câmara do ânodo e produzem elétrons, os quais são então transferidos para o cátodo através de um circuito externo. Os microrganismos na câmara do cátodo posteriormente podem desenvolver a nitrificação e/ou a desnitrificação utilizando os elétrons provenientes do ânodo (SUN et al., 2016). Além de microrganismos, a câmara do cátodo pode conter apenas aceptores de elétrons, dentre eles o oxigênio, que devido ao seu alto potencial de redução e sua disponibilidade vem sendo intensivamente utilizado nos cátodos a ar. A principal limitação deste tipo de cátodo é que eles sofrem com a desvantagem cinética de redução-oxidação mais lenta em condições ambientais, portanto, requerem catalisadores de materiais mais caros, como a platina. Outra desvantagem está relacionada aos elevados requisitos de energia associados ao equipamento mecânico usado para manter o oxigênio dissolvido em concentrações ideais (KOKABIAN; GUDE, 2013). 


\section{¿UNisul}

Quadro 2 - Principais reações em meia célula

\begin{tabular}{|ll|}
\hline Reações em meia célula & Referência \\
Ânodo & \\
$\mathrm{CH}_{3} \mathrm{COO}-4 \mathrm{H}_{2} \mathrm{O} \rightarrow 2 \mathrm{HCO}_{3}^{-}+9 \mathrm{H}^{+}+8 \mathrm{e}^{-}$ & CHENG; GINIGE; KAKSONEN, 2012 \\
$\mathrm{C}_{2} \mathrm{H}_{12} \mathrm{O}_{2^{-}}+4 \mathrm{H}_{2} \mathrm{O} \rightarrow 2 \mathrm{HCO}_{3^{-}}+9 \mathrm{H}^{+}+8 \mathrm{e}^{-}$ & MOOK et al., 2013 \\
$\mathrm{C}+2 \mathrm{H}_{2} \mathrm{O} \rightarrow \mathrm{CO}_{2}+4 \mathrm{H}^{+}+4 \mathrm{e}^{-}$ & MOOK et al., 2013 \\
Cátodo & \\
$2 \mathrm{NO}_{3}^{-}+10 \mathrm{e}^{-}+12 \mathrm{H}^{+} \rightarrow \mathrm{N}_{2}+6 \mathrm{H}_{2} \mathrm{O}$ & CHENG; GINIGE; KAKSONEN, 2012 \\
$\mathrm{NO}_{3}^{-}+2 \mathrm{e}^{-}+2 \mathrm{H}^{+} \rightarrow \mathrm{NO}_{2}^{-}+\mathrm{H}_{2} \mathrm{O}$ & NGUYEN et al., 2015 \\
$\mathrm{NO}_{2}^{-}+\mathrm{e}^{-}+2 \mathrm{H}^{+} \rightarrow \mathrm{NO}^{+} \mathrm{H}_{2} \mathrm{~S}$ & NGUYEN et al., 2015 \\
$\mathrm{NO}^{+} \mathrm{e}^{-}+\mathrm{H}^{+} \rightarrow 0,5 \mathrm{~N}_{2} \mathrm{O}+0,5 \mathrm{H}_{2} \mathrm{O}$ & NGUYEN et al., 2015 \\
$0,5 \mathrm{~N}_{2} \mathrm{O}+\mathrm{e}^{-}+\mathrm{H}^{+} \rightarrow 0,5 \mathrm{~N}_{2}+0,5 \mathrm{H}_{2} \mathrm{O}$ & NGUYEN et al., 2015 \\
$\mathrm{O}_{2}+4 \mathrm{e}^{-}+4 \mathrm{H}^{+} \rightarrow 2 \mathrm{H}_{2} \mathrm{O}$ & DU; LI; GU, 2007 \\
\hline
\end{tabular}

Fonte: Adaptado de SUN et al., 2016.

Esses sistemas possuem vantagens em relação aos processos com células combustíveis convencionais, como baixa temperatura de operação (15ㄷ a $45^{\circ} \mathrm{C}$ ) que pode funcionar de forma eficiente na temperatura ambiente (LARROSA-GUERRERO et al., 2010; TEE et al., 2017); pH neutro para operação, inclusive aumentando a corrente (YE; ZHU; LOGAN, 2016); o eletrocatalisador é composto por bactérias ou proteínas no ânodo (BOROLE et al., 2011); possibilidade de utilização de diferentes tipos de efluentes ou resíduos na forma de biomassa para uso nas reações no ânodo (PANDEY et al., 2016; POTTER, 1911); além de um impacto ambiental menor do que as células combustíveis convencionais, avaliando seus ciclos de vida (PANT et al., 2011).

\subsubsection{Célula Microbiana de Dessalinização e variantes}

O BES foi utilizado para dessalinização de água pela primeira vez em 2009; 0 trabalho de desenvolvimento da MDC foi selecionado como artigo principal na Environmental Science \& Technology no mesmo ano (CAO et al., 2009). O funcionamento da MDC se baseia na capacidade de utilizar a diferença de potencial elétrico gerado entre o ânodo e o cátodo para conduzir a dessalinização in situ. No caso de tratamento de águas residuais, a energia elétrica produzida através da 
conversão da energia química é utilizada na própria unidade (PERAZZOLI et al., 2018).

Diferentemente dos outros BES, as MDC possuem uma terceira câmara de dessalinização que inclui duas membranas: a de troca aniônica (AEM) e a de troca catiônica (CEM) entre o ânodo e o cátodo (CAO et al., 2009), respectivamente. Seu funcionamento parte do princípio de que as bactérias presentes na câmara do ânodo oxidam substratos biodegradáveis e produzem corrente e prótons; então, na câmara de dessalinização os ânions migram para o ânodo e os cátions para o cátodo, através do equilíbrio de carga, dessalinizando assim a solução da câmara do meio (LUO et al., 2012; PERAZZOLI; SANTANA NETO; SOARES, 2020). Outras abordagens também vêm sendo investigadas, como conduzir os sais para a câmara do meio através da dessalinização do anólito e católito (KIM; LOGAN, 2013).

As células combustíveis microbianas osmóticas (OsMFCs), ou MDC osmóticas, são outra variante da MDC, na qual substitui-se a AEM por uma membrana de osmose para retirada de água pura de águas residuais, e impulsionam estudos para regeneração de membranas nesses casos (ZHU et al., 2016).

Ainda existe a célula de dessalinização capacitiva (cMDC), que incorpora a deionização capacitiva nas MDC afim de melhorar a eficiência do processo (FORRESTAL et al., 2012; LIANG et al., 2011; YUAN et al., 2012). Já a tecnologia de dessalinização por eletrólise microbiana e de célula de produção química (MEDCC) produz soluções de ácido clorídrico e hidróxido de sódio através de um sistema de quatro câmaras (CHEN et al., 2012).

As MDC podem ser utilizadas como equipamento independente para degradação de compostos orgânicos e remoção de sal com produção de energia ou pré-tratamento para processos de dessalinização convencionais, como osmose reversa, reduzindo a concentração de sal e minimizando consumo de energia e incrustações na membrana (EBRAHIMI; YOUSEFI KEBRIA; DARZI, 2018). Estima-se que uma MDC pode produzir até $58 \%$ da energia elétrica requerida pelos sistemas de osmose (JACOBSON; DREW; HE, 2011), com possibilidade de redução dos custos operacionais inclusive dos processos convencionais de dessalinização (PERAZZOLI; SANTANA NETO; SOARES, 2018). 


\section{¿unisul sinem}

\subsubsection{Célula de Remediação Microbiana}

As MRC utilizam eletrodos para servir como aceptores de elétrons inesgotáveis (ânodo) ou doadores (cátodo) para remediação de contaminantes do solo (MORRIS; JIN, 2008). Este sistema pode ser composto por um único ou um conjunto de eletrodos sem necessidade de câmaras fechadas, onde microrganismos podem degradar de forma simultânea poluentes orgânicos e produzir energia elétrica. É um processo sustentável, pois elimina o uso de produtos químicos e reduz o custo operacional relacionado com energia elétrica (WANG; REN, 2013).

Em trabalhos realizados na última década verificou-se um aumento elevado na taxa de oxidação/degradação de contaminantes com MRC em comparação aos processos convencionais: no caso de contaminantes de petróleo, chegou a $164 \%$ (MORRIS; JIN, 2008) e no óleo bruto, em 120\% (WANG et al., 2012). Acredita-se que essa degradação elevada seja devido à transferência mais rápida de elétrons por eletrodos com maior capacidade de condução e que a competição entre os microrganismos para alcançar e entregar elétrons aos eletrodos estimule atividades metabólicas mais elevadas e assim a remoção imediata de elétrons através do eletrodo (WANG; REN, 2013).

As aplicações desses sistemas envolvem vários estudos, com diversos contaminantes: diesel, etanol, 1,2-dicloroetano, tricloroeteno, piridina, solventes clorados, perclorato, cromo, urânio, entre outros (WANG; REN, 2013).

\subsubsection{Célula Microbiana Solar}

A MSC é uma tecnologia recentemente desenvolvida que utiliza energia solar para produzir eletricidade ou produtos químicos. Nestas células, os microrganismos fotoautotróficos ou plantas utilizam a energia solar para produção de matéria orgânica através da fotossíntese e usam microrganismos eletroquimicamente ativos no sistema bioeletroquímico para gerar corrente elétrica. Na Figura 5 está apresentado o esquema de funcionamento de uma MSC. Na etapa inicial ocorre a fotossíntese, em seguida a matéria orgânica é transportada para o ânodo, onde ocorre a oxidação anódica por bactérias eletroquimicamente ativas, e, por fim, ocorre a redução catódica de oxigênio em água (STRIK et al., 2011). No Quadro 3 estão apresentadas as reações químicas envolvidas na MSC. 


\section{GESTÃO \& SUSTENTABILIDADE AMBIENTAL

Figura 5 - Princípio de funcionamento de uma MSC

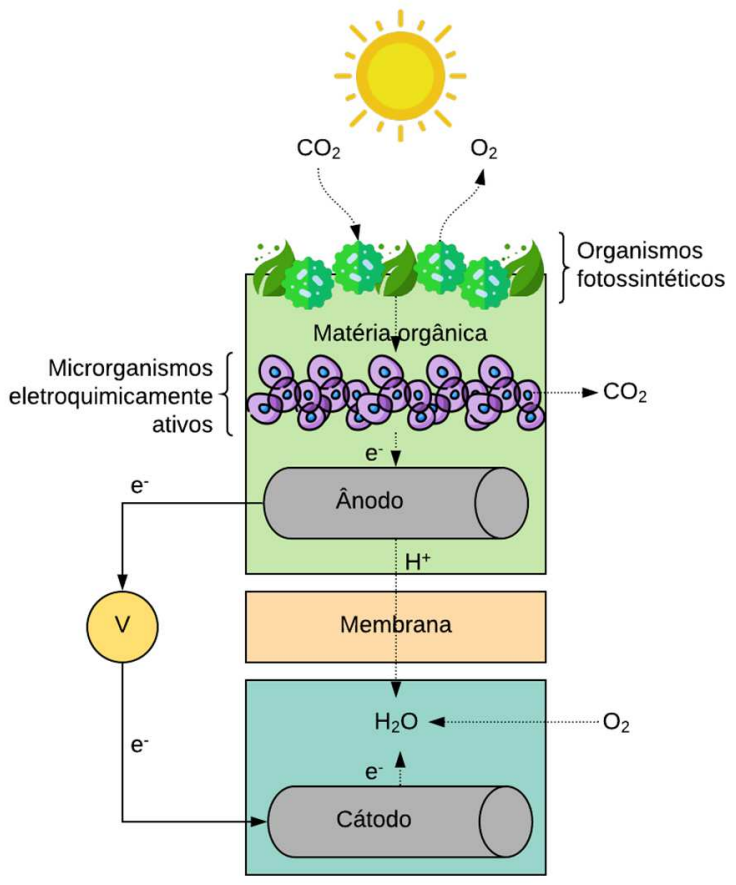

Fonte: Autores, 2020.

Quadro 3 - Reações químicas envolvidas no funcionamento de uma MSC

\begin{tabular}{|ll|}
\hline $6 \mathrm{CO}_{2}+6 \mathrm{H}_{2} \mathrm{O} \rightarrow \mathrm{C}_{6} \mathrm{H}_{12} \mathrm{O}_{6}+6 \mathrm{O}_{2}$ & Fotossíntese \\
$\mathrm{C}_{6} \mathrm{H}_{12} \mathrm{O}_{6}+12 \mathrm{H}_{2} \mathrm{O} \rightarrow 6 \mathrm{HCO}_{3}{ }^{-}+30 \mathrm{H}^{+}+24 \mathrm{e}^{-}$ & Oxidação anódica \\
$6 \mathrm{O}_{2}+24 \mathrm{H}^{+}+24 \mathrm{e}^{-} \rightarrow 12 \mathrm{H}_{2} \mathrm{O}$ & Redução catódica \\
\hline
\end{tabular}

Fonte: Adaptado de STRIK et al., 2011.

Plantas, bactérias fotoautotróficas e algas são responsáveis pela conversão de energia solar em matéria orgânica, e a partir do tipo do organismo o sistema recebe uma classificação. Uma variedade muito ampla de nomes e sistemas relacionados às MSC tem sido relatada na literatura, todavia, todos possuem o mesmo princípio (WANG; REN, 2013). As MSC mais populares são de plantas, que usam os rizodepositores orgânicos excretados das plantas superiores vivas para alimentar as bactérias eletroativas para a produção de eletricidade. Capim e arroz de cana foram usados inicialmente para demonstrar as relações sintróficas, com potências máximas de $67 \mathrm{~mW} \mathrm{~m}^{-2}$ (STRIK et al., 2008) e $26 \mathrm{~mW} \mathrm{~m}^{-2}$ (DE SCHAMPHELAIRE et al., 2008).

As MSC são os únicos BES que não dependem de doadores externos de elétrons como matéria orgânica, utilizam apenas a energia solar para conversão em 
energia elétrica e produtos químicos. Essas células ainda possuem baixa potência e são uma oportunidade de pesquisa para aprimoramento, incluindo diversas áreas do conhecimento (WANG; REN, 2013).

\subsubsection{Célula de Eletrólise Microbiana}

A MEC permite a formação de hidrogênio no cátodo, através da redução de prótons. O uso de uma tensão externa no topo do potencial de uma MFC é a característica principal desse tipo de célula (LIU; GROT; LOGAN, 2005; ROZENDAL et al., 2006). Nesses sistemas, a tensão aplicada varia de 0,6 a 1,0 V, inferior ao processo tradicional da eletrólise da água (1,8-2,0 V) (LOGAN et al., 2008).

A MEC pode utilizar resíduos e materiais renováveis como substratos, alcançando taxas de produção de hidrogênio superiores a $1 \mathrm{~m}^{3} \mathrm{dia}^{-1} \mathrm{~m}^{-3}$ do reator com um rendimento de até $11 \mathrm{~mol} \mathrm{H} \mathrm{H}_{2}$ por mol de glicose (LIU; HU, 2012; LOGAN et al., 2008).

Além do hidrogênio, outros produtos químicos inorgânicos já foram sintetizados no cátodo das MEC: fosfato como estruvita (CUSICK; KIM; LOGAN, 2012), peróxido de hidrogênio através da redução de oxigênio (ROZENDAL et al., 2009) e soluções alcalinas com o acetato como doador de elétrons (RABAEY et al., 2010). Neste último caso podem ser utilizadas como desinfetantes de baixo custo (WANG; REN, 2013).

\subsubsection{Célula de Eletrossíntese Microbiana}

A MES está em ascensão na pesquisa e desenvolvimento nos processos eletroquímicos. O princípio destas células é o uso de elétrons derivados do cátodo para reduzir o dióxido de carbono e outros produtos químicos em uma variedade de compostos orgânicos, visando cadeias com mais carbonos e precursores de produtos químicos de valor agregado desejáveis ou combustíveis como o butanol (LOVLEY; NEVIN, 2011; RABAEY; GIRGUIS; NIELSEN, 2011).

A eletrossíntese é um termo introduzido na última década, sendo que a primeira pesquisa relatada com produção de metano em reator com ânodo abiótico e biocátodo foi em 2009 (CHENG et al., 2009). Posteriormente, com avanços em pesquisas na formação de compostos, obteve-se acetato e 2-oxobutirato a partir de dióxido de carbono (NEVIN et al., 2012). A partir de águas residuais de cervejarias, os seguintes 
compostos já foram obtidos com o biocátodo: metano, acetato e hidrogênio (MARSHALL et al., 2012).

A eletrossíntese possui grande potencial, todavia atualmente ainda existem grandes desafios tecnológicos, incluindo melhoria genética de microrganismos e a necessidade de redução de custos para serem implantados em larga escala (WANG; REN, 2013).

\section{CONSIDERAÇÕES FINAIS}

O presente trabalho analisou as atuais tecnologias envolvidas para sistemas microbianos eletroquímicos e suas aplicações, visando principalmente o potencial energético e o tratamento de resíduos e efluentes.

Verificou-se o princípio de funcionamento das células combustíveis microbianas, que tem como principal produto a geração de energia elétrica, geralmente superior a $0,5 \mathrm{~V} \mathrm{~m}^{-2} \mathrm{com}$ uso de resíduos (SHARMA; LI, 2010). Também foi analisada a célula de remediação microbiana, a qual possui alto potencial de degradação para contaminantes oriundos de derramamentos acidentais de derivados de petróleo, também gerando eletricidade.

Apesar de ainda possuírem baixa potência, as células solares microbianas são as únicas BES que não dependem de doadores externos de elétrons. São dependentes apenas de energia solar inesgotável e com capacidade de conversão em energia e produtos químicos, sendo, portanto, uma tecnologia que merece grande atenção da comunidade científica.

Esses sistemas também se mostraram mais eficientes do que processos tradicionais de obtenção de hidrogênio, como é o caso das células de eletrólise microbiana, que ainda são capazes de produzir soluções alcalinas, peróxido de hidrogênio e fosfato. Além disso, as células de dessalinização microbianas foram desenvolvidas com o objetivo de dessalinizar correntes salinas, como a água do mar, além da geração de energia elétrica, podendo ser acopladas a outras tecnologias para obtenção de águas ainda mais puras.

Por fim, as células de eletrossíntese microbiana se mostram como alternativa para síntese de compostos de valor agregado, com cadeias mais longas de carbono a partir do dióxido de carbono. Todavia, ainda se mostra como uma tecnologia cara. 


\section{GESTÃO \& SUSTENTABILIDADE} AMBIENTAL

\section{¿Unisul sims}

Apesar dos resultados e avanços promissores obtidos até o momento, os sistemas bioeletroquímicos ainda não são aplicados amplamente devido aos custos elevados relacionados aos materiais constituintes. Inúmeros estudos também têm investigado a otimização das condições operacionais e da transferência de elétrons destes sistemas. Desta forma, o desenvolvimento de pesquisas na área ainda é necessário para auxiliar na viabilidade técnica e econômica de aplicação dos BES em escala industrial. Os principais objetivos dessas pesquisas têm sido maximizar a eficiência no tratamento dos resíduos e efluentes e a geração de elétrons livres, que podem ser utilizados para geração de energia elétrica sustentável com a possibilidade de síntese de produtos químicos de valor agregado.

\section{REFERÊNCIAS}

AWE, O. W.; LIU, R.; ZHAO, Y. Analysis of energy consumption and saving in wastewater treatment plant: case study from Ireland. Journal of Water Sustainability, v. 6, n. 2, p. 63-76, 2016.

BOROLE, A. P. et al. Electroactive biofilms: Current status and future research needs. Energy and Environmental Science, v. 4, n. 12, p. 4813-4834, 2011.

$\mathrm{CAO}, \mathrm{X}$. et al. A new method for water desalination using microbial desalination cells. Environmental Science and Technology, v. 43, n. 18, p. 7148-7152, 2009.

CHEN, S. et al. Development of the microbial electrolysis desalination and chemicalproduction cell for desalination as well as acid and alkali productions. Environmental Science and Technology, v. 46, n. 4, p. 2467-2472, 2012.

CHENG, K. Y.; GINIGE, M. P.; KAKSONEN, A. H. Ano-Cathodophilic Biofilm Catalyzes Both Anodic Carbon Oxidation and Cathodic Denitrification. Environmental Science \&Technology, v. 46, n.18, p. 10372-10378, 2012.

CHENG, S. et al. Direct biological conversion of electrical current into methane by electromethanogenesis. Environmental Science and Technology, v. 43, n. 10, p. 3953-3958, 2009.

CUSICK, R. D.; KIM, Y.; LOGAN, B. E. Energy capture from thermolytic solutions in microbial reverse- electrodialysis cells. Science, v. 335, n. 6075, p. 1474-1477, 2012.

DE SCHAMPHELAIRE, L. et al. Microbial fuel cells generating electricity from rhizodeposits of rice plants. Environmental Science and Technology, v. 42, n. 8, p. 3053-3058, 2008.

DU, Z.; LI, H.; GU, T. A state of the art review on microbial fuel cells: a promising technology for wastewater treatment and bioenergy. Chinese Academy of Sciences, v. 25, p. 464-482, 2007.

EBRAHIMI, A.; YOUSEFI KEBRIA, D.; DARZI, G. N. Improving bioelectricity generation and COD removal of sewage sludge in microbial desalination cell. Environmental Technology, v. 39, n. 9, p. 1188-1197, 2018. 


\section{GESTÃO \& SUSTENTABILIDADE} AMBIENTAL

¿unisul

FORNERO, J. J.; ROSENBAUM, M.; ANGENENT, L. T. Electric power generation from municipal, food, and animal wastewaters using microbial fuel cells. Electroanalysis, v. 22, n. 7-8, p. 832-843, 2010.

FORRESTAL, C. et al. Microbial desalination cell with capacitive adsorption for ion migration control. Bioresource Technology, v. 120, p. 332-336, 2012.

HARNISCH, F.; SCHRÖDER, U. From MFC to MXC: chemical and biological cathodes and their potential for microbial bioelectrochemical systems. Chemical Society Reviews, v. 39, n. 11, p. 4433-4448, 2010.

$\mathrm{HE}, \mathrm{Y}$. et al. Assessment of energy consumption of municipal wastewater treatment plants in China. Journal of Cleaner Production, v. 228, p. 399-404, 2019.

JACOBSON, K. S.; DREW, D. M.; HE, Z. Use of a liter-scale microbial desalination cell as a platform to study bioelectrochemical desalination with salt solution or artificial seawater. Environmental Science and Technology, v. 45, n. 10, p. 4652-4657, 2011.

KIM, Y.; LOGAN, B. E. Simultaneous removal of organic matter and salt ions from saline wastewater in bioelectrochemical systems. Desalination, v. 308, p. 115-121, 2013.

KOKABIAN, B.; GUDE V.G. Photosynthetic microbial desalination cells (PMDCs) for clean energy, water and biomass production. Environ. Sci.: Processes Impacts, v. 15, p. 2178, 2013.

LARROSA-GUERRERO, $\mathrm{A}$. et al. Effect of temperature on the performance of microbial fuel cells. Fuel, v. 89, n. 12, p. 3985-3994, 2010.

LIANG, P. et al. Alternate charging and discharging of capacitor to enhance the electron production of bioelectrochemical systems. Environmental Science and Technology, v. 45, n. 15, p. 6647-6653, 2011.

LIAO, Yongxin et al. Past, present and future of Industry 4.0-a systematic literature review and research agenda proposal. International Journal of Production Research, v. 55, n. 12, p. 3609-3629, 2017.

LIMA, ACG.; PASSAMANI, FC. Avaliação do potencial energético do biogás produzido no reator UASB da ETE-UFES. 2012. Trabalho de Conclusão de Curso (Bacharel em Engenharia Ambiental) - Universidade Federal do espirito santo, Vitória, 2012.

LIU, H.; GROT, S.; LOGAN, B. E. Electrochemically assisted microbial production of hydrogen from acetate. Environmental Science and Technology, v. 39, n. 11, p. 4317-4320, 2005.

LIU, H.; HU, H. Microbial electrolysis: novel biotechnology for hydrogen production from biomass. Microbial Technologies in Advanced Biofuels Production, v. 9781461412083, p. 93-105, 2012.

LOGAN, B. E. et al. Microbial electrolysis cells for high yield hydrogen gas production from organic matter. Environmental Science and Technology, v. 42, n. 23, p. 86308640, 2008.

LOGAN, B. E.; RABAEY, K. Conversion of wastes into bioelectricity and chemicals by using microbial electrochemical technologies. Science, v. 337, n. 6095, p. 686-690, 


\section{GESTÃO \& SUSTENTABILIDADE} AMBIENTAL

\section{¿unisul}

2012.

LOVLEY, D. R.; NEVIN, K. P. A shift in the current: new applications and concepts for microbe-electrode electron exchange. Current Opinion in Biotechnology, v. 22, n. 3, p. 441-448, 2011.

LUO, H. et al. Microbial desalination cells for improved performance in wastewater treatment, electricity production, and desalination. Bioresource Technology, v. 105, p. 60-66, 2012.

MAGGIO, G.; CACCIOLA, G. When will oil, natural gas, and coal peak? Fuel, v. 98, n. 2012, p. 111-123, 2012.

MARSHALL, C. W. et al. Electrosynthesis of commodity chemicals by an autotrophic microbial community. Applied and Environmental Microbiology, v. 78, n. 23, p. 8412-8420, 2012.

MOHAN, S. V. et al. Microbial fuel cell: critical factors regulating bio-catalyzed electrochemical process and recent advancements. Renewable and Sustainable Energy Reviews, v. 40, p. 779-797, 2014.

MOHER, D. et al. Preferred reporting items for systematic reviews and metaanalyses: the PRISMA statement. Int J Surg, v. 8, n. 5, p. 336-341, 2010.

MOOK, W. T. et al. Journal of Industrial and engineering chemistry a review on the effect of bio-electrodes on denitrification and organic matter removal processes in bioelectrochemical systems. Journal of Industrial and Engineering Chemistry, v. 19, n. 1, p. 1-13, 2013.

MORRIS, J. M.; JIN, S. Feasibility of using microbial fuel cell technology for bioremediation of hydrocarbons in groundwater. Journal of Environmental Science Health A Toxic Hazardous Substances and Environmental Engineering, v. 43, n. 1, p. 18-23, 2008.

NEVIN, K. P. et al. Microbial electrosynthesis: feeding microbes electricity to convert carbon dioxide and water to multicarbon extracellular organic compounds kelly. Microbiology Australia, v. 7, n. February, p. 330-338, 2012.

NGUYEN, V. K. et al. Autotrophic denitri fi cation performance and bacterial community at biocathodes of bioelectrochemical systems with either abiotic or biotic anodes. Journal of Bioscience and Bioengineering, v. 119, n. 2, p. 180-187, 2015.

PANDEY, P. et al. Recent advances in the use of different substrates in microbial fuel cells toward wastewater treatment and simultaneous energy recovery. Applied Energy, v. 168, p. 706-723, 2016.

PANT, D. et al. An introduction to the life cycle assessment (LCA) of bioelectrochemical systems (BES) for sustainable energy and product generation: relevance and key aspects. Renewable and Sustainable Energy Reviews, v. 15, n. 2, p. 1305-1313, 2011.

PERAZZOLI, S. et al. Biological fuel cells produce bioelectricity with in-situ brackish water purification. Water Science and Technology, v. 78, n. 2, p. 301-309, 2018.

PERAZZOLI, Simone; SANTANA NETO, José Pedro de; SOARES, Hugo M. Anoxicbiocathode microbial desalination cell as a new approach for wastewater remediation 
and clean water production. Water Science And Technology, v. 81, n. 3, p. 550-563, 2020.

PERAZZOLI, Simone; SANTANA NETO, José Pedro de; SOARES, Hugo M.. Prospects in bioelectrochemical technologies for wastewater treatment. Water Science And Technology, v. 78, n. 3, 1237-1248, 2018.

POTTER, M. C. Electrical Effects accompanying the Decomposition of Organic Compounds. Proc. R. Soc. Lond., v. 84, ed. 571, p. 260-276, 1911.

RABAEY, K. et al. High current generation coupled to caustic production using a lamellar bioelectrochemical system. Environmental Science and Technology, v. 44, n. 11, p. 4315-4321, 2010.

RABAEY, K.; GIRGUIS, P.; NIELSEN, L. K. Metabolic and practical considerations on microbial electrosynthesis. Current Opinion in Biotechnology, v. 22, n. 3, p. 371377, 2011.

RAHIMNEJAD, M.; ADHAMI, A. Microbial fuel cell as new technology for bioelectricity generation: a review. Alexandria Engineering Journal, v. 54, n. 3, p. 745-756, 2015.

RITTER, S. K. Green Solutions to Global Problems. Science \& Technology, p. 31-33, 2003.

ROZENDAL, R. A. et al. Principle and perspectives of hydrogen production through biocatalyzed electrolysis. International Journal of Hydrogen Energy, v. 31, n. 12, p. 1632-1640, 2006.

ROZENDAL, R. A. et al. Efficient hydrogen peroxide generation from organic matter in a bioelectrochemical system. Electrochemistry Communications, v. 11, n. 9, p. 1752-1755, 2009.

SANTORO, C. et al. Microbial fuel cells : from fundamentals to applications . A review. Journal of Power Sources, v. 356, p. 225-244, 2017.

SARATALE, R. G. et al. Microbiome involved in microbial electrochemical systems (MESs): a review. Chemosphere, v. 177, p. 176-188, 2017.

SHARMA, Yogesh; LI, Baikun. The variation of power generation with organic substrates in single-chamber microbial fuel cells (SCMFCs). Bioresource Technology, v. 101, n. 6, p. 1844-1850, 2010.

STRIK, D. P. B. T. B. et al. Green electricity production with living plants and bacteria ia a fuel cell. International Journal of Energy Research, v. 32, n. 9 p. 870-876, 2008.

STRIK, D. P. B. T. B. et al. Microbial solar cells: Applying photosynthetic and electrochemically active organisms. Trends in Biotechnology, v. 29, n. 1, p. 41-49, 2011.

SUN, H. et al. Performance and recent improvement in microbial fuel cells for simultaneous carbon and nitrogen removal: a review. JES, v. 39, p. 242-248, 2016.

TEE, P. F. et al. Effects of temperature on wastewater treatment in an affordable microbial fuel cell-adsorption hybrid system. Journal of Environmental Chemical Engineering, v. 5, n. 1, p. 178-188, 2017.

UHLMANN, I.R.; FRAZZON, E.M. Production rescheduling review: opportunities for industrial integration and practical applications. Journal of Manufacturing 


\section{GESTÃO \& SUSTENTABILIDADE} AMBIENTAL

\section{¿UISUl}

Systems, v. 49, p. 186-193, 2018.

U.S. ENERGY INFORMATION ADMINISTRATION. International Energy Outlook 2019: with projections to 2050. Washington: U.S. Energy Information Administration, 2019.

WANG, H.; REN, Z. J. A comprehensive review of microbial electrochemical systems as a platform technology. Biotechnology Advances, v. 31, n. 8, p. 1796-1807, 2013.

WANG, J. et al. A bibliometric review of research trends on bioelectrochemical systems. Current Science, v. 109, n. 12, p. 2204-2211, 2015.

WANG, X. et al. Bioelectrochemical stimulation of petroleum hydrocarbon degradation in saline soil using U-tube microbial fuel cells. Biotechnology and Bioengineering, v. 109, n. 2, p. 426-433, 2012.

WINFIELD, J. et al. A review into the use of ceramics in microbial fuel cells. Bioresource Technology, v. 215, p. 296-303, 2016.

YE, Y.; ZHU, X.; LOGAN, B. E. Effect of buffer charge on performance of air-cathodes used in microbial fuel cells. Electrochimica Acta, v. 194, p. 441-447, 2016.

YUAN, L. et al. Capacitive deionization coupled with microbial fuel cells to desalinate low-concentration salt water. Bioresource Technology, v. 110, p. 735-738, 2012.

ZHU, X. Z. et al. Insights into enhanced current generation of an osmotic microbial fuel cell under membrane fouling condition. Journal of Membrane Science, v. 504, p. 4046, 2016. 